\title{
AKTIVITAS ANTI JAMUR FRAKSI AKTIF EKSTRAK ETANOL UMBI BAWANG RAMBUT (Allium chinense G.Don) TERHADAP JAMUR Candida albicans
}

\author{
Supomo $^{1)}$, Idriana ${ }^{2)}$, Audinah Eka ${ }^{3)}$, Indra ${ }^{4)}$, Miftahul Huda ${ }^{5)}$, Husnul Warnida ${ }^{6}$ \\ Jurusan Farmasi, Sekolah Tinggi Ilmu Kesehatan Samarinda, Samarinda, Indonesia \\ email:fahmipomo@gmail.com
}

\begin{abstract}
Abstrak
Tumbuhan umbi bawang rambut (Allium chinense G.Don) memiliki efek sebagai antijamur karena mengandung metabolit sekunder seperti flavanoid, alkaloid dan saponin. Tujuan penelitian ini adalah mengetahui aktivitas antijamur ekstrak umbi bawang rambut melalui proses fraksinasi menggunakan pelarut $N$-heksan, etil asetat, kloroform dan etanol-air. Penelitian yang dilakukan adalah penelitian eksperimental. Sampel yang digunakan adalah umbi bawang rambut yang diperoleh di kampung Kelasan kecamatann Sungai Payang Kutai Kartanegara. Penelitian ini menggunakan metode maserasi dengan pelarut etanol $70 \%$, metode uji aktivitas antijamur berdasarkan metode difusi cakram terhadap jamur Candida albicans dengan konsentrasi 5\%, 10\%, 25\%, dan 50\%, dengan kontrol negatif DMSO 50\%. Hasil penelitian menunjukkan bahwa semua fraksi dari ekstrak etanol umbi bawang rambut memiliki aktivitas antijamur. Aktivitas antijamur fraksi etil asetat memberikan daya hambat yang paling besar terhadap Candida albicans diantara fraksi lainnya.
\end{abstract}

Kata kunci: candida albicans; Allium chinense G. Don; antijamur; fraksi

\begin{abstract}
Allium chinense has an antifungal effect because it contains secondary metabolites such as flavonoids, alkaloids and saponins. The purpose of this research is to investigate the antifungal activity of Allium chinense extract through fractionation process using $N$-hexane solvent, ethyl acetate, chloroform and ethanol-water. The research is experimental research. Samples used are the Allium chinense found in Kelasan Sungai Payang Kutai Kartanegara. Using maseration method with $70 \%$ ethanol solvent, antifungal activity test method based on disc diffusion method on Candida albicans fungi with concentration of 5\%, $10 \%, 25 \%$, and 50\%, with negative control of DMSO 50\%. The results showed that all fractions of Allium chinense ethanol extract had antifungal activity. The antifungal activity of the ethyl acetate fraction provides the greatest resistance to Candida albicans among other fractions.
\end{abstract}

Keywords: candida albicans, allium chinense G. Don, antifungal, fraction

\section{PENDAHULUAN}

Obat antibakteri telah banyak dikembangkan secara luas, berbeda dengan obat antijamur yang masih sangat terbatas pengobatannya. Penyakit yang disebabkan oleh Candida dikenal dengan kandidiasis atau kandidosis yaitu suatu penyakit jamur yang bersifat akut dan subakut yang dapat mengenai mulut, vagina, kulit, kuku, paru-paru dan saluran pencernaan. Penyakit ini ditemukan di seluruh dunia dan dapat menyerang semua umur, baik laki-laki maupun perempuan (Jawetz, dkk., 1996).

Seiring perkembangan zaman yang semakin canggih, pemakaian dan pemanfaatan obat tradisional di Indonesia mengalami kemajuan yang sangat pesat. Obat-obat tradisional masih banyak digunakan masyarakat sebagai salah satu alternatif pengobatan, karena berasal dari tumbuhan dan bahan alami murni yang memiliki efek samping, bahaya, dan resiko yang jauh lebih rendah dibandingkan dengan obat kimia (Rochani, 2009).

Tumbuhan umbi bawang rambut (Allium chinense G. Don) merupakan salah satu alternatif yang dapat digunakan sebagai pengobatan. Secara empiris masyarakat suku Dayak Kenyah di desa Teluk Selimau, kabupaten Bulungan, provinsi Kalimantan Utara biasanya memanfaatkan umbi dan daun dari tumbuhan ini untuk pengobatan diare, radang tenggorokan, dan jantung. Tanaman ini biasanya digunakan masyarakat setempat untuk pengobatan diare dengan cara meminum air rebusan dari daun bawang rambut tersebut (Sari, 2016).

Bagian yang dapat digunakan sebagai obat yaitu bunga, daun, dan umbi. Bunga bawang rambut dapat mengobati cacingan. Daunnya dapat digunakan untuk mengobati masuk angin, diare, 
cacar, kudis, dan gatal-gatal. Umbi bawang rambut dapat digunakan untuk mengobati jantung koroner, kejang jantung, sinusitis, radang tenggorokan, radang perut dan muntah (Zuhud, dkk., 2013).

Menurut Saihatin (2016), zona hambat paling besar dari ekstrak etanol umbi bawang rambut terhadap bakteri Escherichia coli dengan konsentrasi $500 \mathrm{mg} / \mathrm{ml}$ sebesar 22,36 mm. Henoch (2016), zona hambat paling besar dari ekstrak etanol umbi bawang rambut bakteri Staphylococcus aureus dengan konsentrasi 500 $\mathrm{mg} / \mathrm{ml}$ sebesar 7,13 mm. Hasil penelitian Grovy (2015), aktivitas antimikroba ekstrak bawang rambut dengan menggunakan 5 pelarut yaitu etanol $70 \%$, etanol $96 \%$, etil asetat, N-heksana dan air dengan mikroba uji yaitu E. Coli, S. Typhi, S. Aureus, B. subtilis dan C. Albicans menghasilkan daya hambat paling besar pada konsentrasi 25 $\mathrm{mg} / \mathrm{ml}$ sebesar $18,32 \pm 0,66 \mathrm{~mm}$ pada bakteri candida albicans. Penelitian ini menggunakan dari fraksi etil asetat karena diharapkan senyawa aktif atau metabolit yang terkandung dalam tumbuhan umbi bawang rambut dapat dipisahkan berdasarkan tingkat kepolarannya. Tujuan penelitian ini untuk mengetahui potensi fraksi aktif ekstrak umbi bawang rambut terhadap jamur candida albicans.

\section{METODE PENELITIAN}

Desain penelitian ini adalah eksperimental laboratorium rancangan penelitian acak lengkap. Kegiatan yang dilakukan adalah pembuatan seri konsentrasi uji, penapisan aktivitas anti bakteri, dan uji antibakteri.

\section{Alat dan bahan}

Alat yang digunakan pada penelitian ini alat-alat gelas (pyrex), rak tabung reaksi, blender, vortex, hotplate (Ceran $\left.{ }^{\circledR}\right)$, sendok tanduk, pinset, kertas coklat, lampu spiritus, autoclaf, incubator (Hemmert $\AA)$, magnetic stirer, timbangan analitik (Ohaus $®)$, jangka sorong (Enzo $\left.{ }^{\circledR}\right)$, penangas air, laminar airflow cabinet, spektofotometri, mesh 60 .

Bahan yang digunakan pada penelitian ini yaitu umbi bawang rambut, Sabouraud Dekstrosa Agar (SDA), Nutrient Broth (NB), suspensi jamurCandida albicans, Kertas cakram (Paperdisk), plastik wrap, alkohol 70\%, etil asetat, n-hesan, alumunium foil, kertas saring, tissue, kapas steril, kassa, air suling, DMSO $50 \%$, Metylene blue, $\mathrm{HCl} 2 \mathrm{~N}, \mathrm{HCl} \mathrm{p}$, $\mathrm{FeCl}_{3}, \mathrm{NaOH}, \mathrm{H}_{2} \mathrm{SO}_{4}$, Serbuk $\mathrm{Mg}$, Amil alkohol, pereaksi Meyer, pereaksi Bouchardat, pereaksi dragendrof.

\section{Prosedur kerja \\ Ekstraksi Umbi Bawang Rambut}

Pembuatan ekstrak umbi bawang rambut dilakukan dengan cara menimbang 200 gram ekstrak kemudian dilarutkan dengan 2 L pelarut etanol $70 \%$ (1:10) pada wadah kaca sampai seluruh serbuk terendam didiamkan selama 5 hari sambil diaduk berulang-ulang (3 kali sehari). Hasil ekstraksi disaring untuk memisahkan maserat dengan filtrat. Maserasi juga dilakukan dengan berulang (remaserasi), dengan $2 \mathrm{~L}$ pelarut etanol $70 \%$. Kemudian disaring, semua maserat dikumpulkan dan diuapkan diatas penangas air hingga diperoleh ekstrak kental(Voigt, 1995.

\section{Analisis Fitokimia Uji Alkaloid}

Sebanyak 10 tetes ekstrak ditambahkan 2 tetes pereaksi, keberadaan alkaloid dalam sampel ditunjukkan dengan terbentuk endapan putih pada pereaksi Meyer, endapan coklat sampai hitam pada pereaksi Bouchardat dan endapan jingga sampai merah coklat pada pereaksi Dragendorf.

\section{Uji Flavonoid}

10 tetes ekstrak dimasukkan ditambahkan 2 tetes $\mathrm{HCl}$ pekat, lalu ditambahkan serbuk $\mathrm{Mg}$ serta ditambahkan amil alkohol, amati perubahan. Bila terbentuk warna kuning, orange atau merah pada lapisan amil alkohol memberikan indikasi adanya flavonoid.

\section{Uji Saponin}

10 tetes ekstrak dimasukkan ditambahkan 5 tetes air panas, dikocok selama 15 menit, maka akan terbentuk busa ditambahkan 1 tetes $\mathrm{HCl} 2 \mathrm{~N}$, amati perubahan. Bila terbentuk busa permanen memberikan indikasi adanya saponin.

\section{Uji Tanin}

10 tetes ekstrak dimasukkan ke dalam tabung reaksi, lalu ditambahkan 2 tetes larutan besi (III) klorida $1 \%$, amati perubahan. Bila terbentuk warna biru kehitaman memberikan indikasi adanya senyawa tanin.

\section{Fraksinasi}

Fraksinasi yang paling mudah yaitu dengan metode partisi cair-cair. Teknik ini menggunakandua pelarut yang tidak bercampur dalam corong pisah dansenyawa didistribusikan dalam kedua pelarutsesuai koefisien partisinya. Metode ini relatif mudah dan sangat efektif sebagai langkah pertama dalam pemisahan ekstrak kasar (Sarker,dkk., 2006). 
Proses fraksinasi menggunakan fraksinasi bertingkat, dilakukan secara modifikasi dengan cara menimbang ekstrak kental sebanyak 10 gram, dilarutkan dengan etanol $70 \%$ dan air dalam 100 $\mathrm{mL}$ (1:1). Selanjutnya difraksinasi dengan $\mathrm{n}$ heksan (3 x $50 \mathrm{ml})$, etil asetat $(3 \times 50 \mathrm{ml})$, kloroform (3 x $50 \mathrm{ml})$. Masing-masing pelarut dimasukkan bergantian sesuai dengan kelarutannya, kemudian di uapkan di atas tangas air (Septiana, 2013).

\section{Uji Aktivitas Antijamur}

Uji aktivitas antijamur dilakukan dengan metode difusi cakram. Jamur Candida albicansditumbuhkan pada media SabouraudDextr ose Agar (SDA). Biakan jamurCandida albicans kemudian diencerkan dengan Nutrient Broth menggunakan metode McFarland 0.5 (setara dengan $\left.10^{8} \mathrm{CFU} / \mathrm{ml}\right)$, kemudian diukur kekeruhannya menggunakan spektrofotometri UVVis dengan range $75 \%$ pada panjang gelombang $580 \mathrm{~nm}$ (Nur, 2014). Selanjutnya dilakukan identifikasi jamur dengan menggunakan pewarna metylene blue.

Suspensi jamur yang telah diukur kekeruhannya menggunakan spektrofotometri UVVis kemudian dijenuhkan dengan menggunakan cotton bud lalu diswab kepermukaan medium agar, lalu kertas cakram steril yang sudah direndam dalam masing-masing pelarut $n$-heksan, etil asetat, kloroform dan etanol-air dengan konsentrasi 5\%, $10 \%$, 25\%, dan 50\% serta kontrol negatif DMSO $50 \%$ diletakkan diatas medium agar. Selanjutnya diinkubasi pada suhu $25^{\circ} \mathrm{C}-30^{\circ} \mathrm{C}$ selama 72 jam. Zona bening yang terbentuk di sekeliling cakram disk diukur menggunakan jangka sorong. Kemudian data yang didapat dari hasil zona hambat yang terbentuk dari masing-masing fraksi diuji menggunakan SPSS dengan metode One Way Anova untuk mengetahui apakah data berdistribusi normal atau tidak, lalu dilanjutkan dengan uji $L S D$ untuk mengetahui perbedaan secara nyata pada perbedaan perlakuan dan hasil yang diperoleh.

\section{HASIL DAN PEMBAHASAN Analisis Fitokimia}

Hasil analisis fitokimia umbi bawang rambut menunjukkan adanya senyawa-senyawa alkaloid, flavonoid dan saponin. Hasil uji fitokimia umbi bawang rambut dapat dilihat pada tabel 1.
Tabel 1. Analisis Fitokimia Umbi Bawang Rambut

\begin{tabular}{|c|c|c|c|}
\hline $\begin{array}{c}\text { Uji } \\
\text { Fitokimia }\end{array}$ & Pereaksi & Hasil & Keterangan \\
\hline \multirow{3}{*}{ Alkaloid } & $\begin{array}{l}\text { Mayer } \\
\text { Bouchar-dat }\end{array}$ & $\begin{array}{l}\text { Endapan } \\
\text { putih/kuning }\end{array}$ & + \\
\hline & Dragen-drof & $\begin{array}{l}\text { Endapan } \\
\text { coklat } \\
\text { kehitaman }\end{array}$ & - \\
\hline & & $\begin{array}{l}\text { Endapan } \\
\text { merah bata }\end{array}$ & + \\
\hline Flavonoid & $\begin{array}{l}\mathrm{HCl} \text { pekat, } \\
\text { Serbuk Mg, } \\
\text { Amil } \\
\text { alcohol }\end{array}$ & $\begin{array}{l}\text { Merah, } \\
\text { Kuning, } \\
\text { jingga pada } \\
\text { lapisan Amil } \\
\text { alkohol }\end{array}$ & + \\
\hline Tanin & $\mathrm{FeCl}_{3} 1 \%$ & $\begin{array}{l}\text { Biru/hijau } \\
\text { kehitaman }\end{array}$ & - \\
\hline Saponin & $\begin{array}{l}\text { Air suling } \\
\text { dan } \mathrm{HCl} \\
\text { pekat }\end{array}$ & $\begin{array}{l}\text { Busa } \\
\text { permanen }\end{array}$ & + \\
\hline
\end{tabular}

$(+)$ : positif mengandung metabolit sekunder

$(-)$ : negatif mengandung metabolit sekunder

Berdasarkan uji skrining fitokimia dari ekstrak umbi bawang rambut menyatakan positif mengandung saponin, alkaloid dan flavonoid.Hal ini sesuai dengan penelitian Supomo,dkk (2020) bahwa ekstrak etanol umbi bawang rambut mengandung metabolit sekunder saponin, flavonoid dan alkaloid. Metabolit sekunder yang ada pada tanaman ini memiliki aktivitas antimikroba. Saponin dapat menurunkan tegangan permukaan sehingga dapat menghambat pertumbuhan jamur (Puspitasari, dkk., 2009). Saponin memiliki aktivitas sebagai antifungi. Mekanisme aksi dari saponin terhadap jamur melibatkan pembentukan kompleks dengan sterol pada membran plasma sehingga menghancurkan semipermeabilitas sel lalu mengarah kepada kematian sel (Kumalasari, dkk., 2011). Flavonoid mengandung gugus fenol yang dapat mendenaturasikan protein dan menyebabkan lisis pada membran sel yang bersifat irreversible (Robinson, 1995).

\section{Hasil Identifikasi Fungi}

Proses identifikasi yang dilakukan untuk mengidentifikasi kemurnian dari mikroba uji adalah dengan melakukan pewarnaan, pewarnaan organisme adalah prosedur mewarnai mikroorganisme dengan menggunakan zat warna yang dapat menonjolkan struktur mikroba yang diamati, dengan dilakukan pewarnaan maka dapat diketahui mikroba uji yang akan digunakan tidak 
terkontaminasi oleh bakteri lain (Rahmawati, 2015).

Perbedaan warna yang dihasilkan setelah proses pewarnaan disebabkan oleh perbedaan struktur dinding sel. Setelah dilakukan identifikasi mikroba uji didapat kemiripan dengan jamur Candida albicans dibuktikan dengan adanya sel ragi dan mycelium yang didapatkan hal ini menyatakan bahwa jamur Candida yang diteliti adalah benar jamur Candida albicans dan tidak terkontaminasi dengan bakteri lainnya.Hasil uji mikroskopik jamur candida albicans tersaji pada gambar 1 .

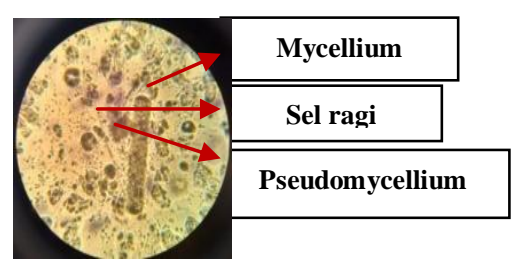

Gambar 1. Hasil uji mikroskopik jamur Candida albicans

\section{Aktivitas Antijamur}

Pengukuran aktivitas antijamur menunjukkan bahwa semua fraksi dapat menghambat pertumbuhan jamur Candida albicans pada konsentrasi 5\% dengan diameter zona hambat yang berbeda-beda. Fraksi etil asetat memiliki aktivitas antijamur tertinggi daripada fraksi lainnya. Hasil pengukuran zona hambat pada fraksi umbi bawang rambut tersaji pada tabel 2 .

Tabel 2. Zona Hambat Fraksi Umbi Bawang Rambut

\begin{tabular}{lcccc}
\hline \multirow{1}{c}{ Fraksi } & \multicolumn{4}{c}{$\begin{array}{c}\text { Zona hambat pada setiap } \\
\text { konsentrasi (mm) }\end{array}$} \\
& $5 \%$ & $10 \%$ & $25 \%$ & $50 \%$ \\
\hline n-heksan & 16,71 & 15,09 & 15,44 & 16,91 \\
Etil asetat & 18,14 & 21,65 & 22,43 & 24,69 \\
Kloroform & 17,50 & 19,03 & 20,20 & 20,72 \\
Etanol-air & 13,28 & 12,63 & 15,53 & 20,31 \\
DMSO 50\% & 0 & 0 & 0 & 0 \\
\hline
\end{tabular}

Pada hasil pengamatan didapatkan diameter zona hambat yang terbentuk dari masing-masing konsentrasi, dapat dilihat dari hasil zona hambat yang terbentuk bahwa semua fraksi dari ekstrak etanol umbi bawang rambut dapat menghambat aktivitas antijamur terhadap Candida albicans. Diameter terbesar terdapat pada fraksi etil asetat pada konsentrasi $50 \%$ dengan rata-rata zona hambat sebesar 24,69 $\mathrm{mm}$ dan diameter terkecil terdapat pada fraksi etanol-air pada konsentrasi $5 \%$ dengan rata-rata zona hambat sebesar 13,28 mm. Hal ini sesuai dengan penelitian yang dilakukan oleh Grovy (2015), bahwa ekstrak etil asetat umbi bawang rambut menghasilkan zona hambat paling besar diantara ekstrak lainnya, dengan zona hambat sebesar 18,32 $\pm 0,66$, dan setelah dilakukan fraksinasi didapat hasil uji aktivitas antijamur umbi bawang rambut dengan zona hambat yang lebih besar ditunjukkan dari konsentrasi 5\% dengan rata-rata sebesar 20,45 $\mathrm{mm}$. Kontrol negatif tidak memberikan aktivitas antimikroba karena rata-rata zona hambat yang diberikan tidak ada atau sama dengan nol hal itu disebabkan pada kontrol negatif menggunakan pelarut DMSO. Pelarut DMSO merupakan pelarut organik dan tidak bersifat bakterisidal(Reynolds, 1996)..DMSO dipilih sebagai pelarut ekstrak karena tidak memiliki aktivitas sebagai antijamur sehingga tidak berpengaruh pada besarnya aktivitas penghambatan ekstrak terhadap jamur uji yang dibuktikan dengan uji kontrol negatif.

Umbi bawang rambut mampu menghambat pertumbuhan jamur Candida albicans karena mempunyai daya antimikroba, hal itu disebabkan umbi bawang rambut mengandung metabolit sekunder berupa saponin, flavonoid dan alkaloid. Pelarut etil asetat dapat digunakan untuk mengekstrak senyawa metabolit sekunder yang bersifat semi polar seperti flavonoid.Menurut (Markham, 1988) pelarut etil asetat merupakan pelarut yang digunakan untuk mengekstrak senyawa dengan polaritas menengah seperti flavonoid dalam bentuk O-glikosida dan tannin .

Selanjutnya dilakukan analisis data dengan menggunakan SPSS versi 20. Data yang didapat dari masing-masing zona hambat dilakukan pengujian untuk mengetahui apakah data berdistribusi normal atau tidak. Uji normalitas pada penelitian ini menghasilkan nilai $\mathrm{p}>0,05$. Hal ini menunjukkan bahwa data berdistribusi normal begitu pula dengan hasil uji variansi dengan nilai $\mathrm{p}>0,05$ yang menunjukkan data memenuhi syarat untuk dilakukan uji One-Way Anova. Setelah diketahui bahwa terjadi perbedaan bermakna antara konsentrasi, maka perlu dilakukan analisis Post Hoc untuk mengetahui kelompok mana yang berbeda secara bermakna.

\section{KESIMPULAN DAN SARAN}

Berdasarkan hasil penelitian yang diperoleh dapat disimpulkan bahwa pada setiap fraksi dari ekstrak etanol umbi bawang rambut 
(Alliumchinense G. Don) memiliki aktivitas antijamur terhadap Candida albicans dan pada fraksi etil asetat menghasilkan zona hambat yang paling besar diantara fraksi lainnya.

Saran kepada peneliti selanjutnya agar dapat melakukan elusidasi struktur untuk mendapatkan senyawa aktif yang berkhasiat sebagai anti jamur.

\section{REFERENSI}

Grovy, F.N. (2015). "Aktivitas Antimikrob dan Identifikasi Senyawa Bioaktif Ekstrak Bawang Batak (Allium chinense G. Don)". Skripsi. Bogor: Sekolah Pascasarjana Institut Pertanian Bogor.

Henoch, T. (2016). "Uji Aktivitas Antibakteri Ekstrak Etanol Daun Bawang Rambut (Allium chinense G. Don) Terhadap Bakteri Staphylococcus aureus ATCC 12228". Karya Tulis Ilmiah. Samarinda: D-III Farmasi Akademi Farmasi Samarinda. Hal: 29.

Jawetz, E., Melnick, J.L., dan Adelberg, E.A. (1996). Mikrobiologi Kedokteran. Edisi XX. Jakarta: Penerbit Salemba Medika.

Kumalasari, E., Sulistyani, N. (2011). ”Antifungal Activity of Ethanol Extract of Binahong Stem (Anredera cordifolia (Tenore) Steen) Against Candida albicans and The Phytochemical Screening”. Jurnal Ilmiah Kefarmasian. 1(2): 5162.

Markham, K.R. (1988). Cara Mengidentifikasi Flavonoid. Diterjemahkan oleh Padmawinata, K. Bandung: Penerbit ITB. Hal: 5-6

Puspitasari, A., Sudarso, Asrining, B.D. (2009). "Aktivitas Antijamur Ekstrak Etanol Soxhletasi dan Maserasi Daun Mimba (Azadirachta indica) terhadap Candida albicans". PHARMACY. 6(2).

Rahmawati, M. (2015). "Uji Aktivitas Antimikroba Ekstrak Etanol dan Air Rimpang Pacing (Costus spiralis) Terhadap Bakteri Escherichia coli, Shigella dysenterie, Salmonella typhimurium, Bacillus subtilis, Staphylococcus aureus Serta Fungi Candida albicans". Skripsi. Jakarta: Fakultas Kedokteran dan Ilmu Kesehatan Program Studi Farmasi UIN Syarif Hidayatullah. Hal: 29.

Reynolds, J.E.F. (1996). Martindale, The Extra Pharmacopeia $3 I^{\text {th }}$ Edition. The Royal Pharmaceutical Society Press. London. p: 114.
Robinson, T. (1995). Kandungan Organik Tumbuhan Tinggi. Edisi VI. Bandung: Penerbit ITB.

Rochani, N. (2009). "Uji Aktivitas Antijamur Ekstrak Daun Binahong (Anrederacordifolia (Tenore) Steen) Terhadap Candida Albicans Serta Skrining Fitokimianya". Skripsi. Surakarta: Fakultas Farmasi Universitas Muhammadiyah Surakarta. Hal: 3.

Saihatin, U. (2016). "Uji Aktivitas Antibakteri Ekstrak Etanol Umbi Bawang Rambut (Allium chinense G. Don) Terhadap Bakteri Escherichia Coli ATCC 8939". Karya Tulis Ilmiah. Samarinda: DIII Farmasi Akademi Farmasi Samarinda. Hal: 33-34.

Sari, N. (2016). "Uji Aktivitas Antibakteri Ekstrak Etanol Daun Bawang Rambut (Allium chinense G. Don) Terhadap Bakteri Escherichia Coli ATCC 8939". Karya Tulis Ilmiah. Samarinda: DIII Farmasi Akademi Farmasi Samarinda. Hal: 5.

Sarker, D.S., Latif, Z., Gray, I.A. (2005). Natural Products Isolation. 2nd Ed. New Jersey: Humana Press. Hal: 6.

Septiana, E.I. (2013). "Aktivitas Antibakteri dan Bioautografi Fraksi Etanol-Air Ekstrak Aseton Kulit Buah Kakao (Theobroma cacao L.) Terhadap Streptococus mutans dan Escherichia coli’. Surakarta: Fakultas Farmasi Universitas Muhammadiyah Surakarta. Hal: 4.

Supomo, Husnul Warnida, Bagus Moch Sahid. (2019). Perbandingan Metode Ekstraksi Ekstrak Umbi Bawang Rambut (Allium Chinenseg.Don.) Menggunakan Pelarut Etanol 70\%Terhadap Rendemen Dan Skrining Fitokimia. Jurnal Riset Kefarmasian Indonesia.1(1):30-40.

Voigt, R. (1995). Buku Pelajaran Teknologi Farmasi. Diterjemahkan oleh Noerono, S.S., Mathilda, B., Widianto. Yogyakarta: UGM Press. Hal: 564.

Zuhud, E.A.M., Siswoyo. E., Sandara, A., Hikmat, dan E. Adhiyanto. (2013). Buku Acuan Umum Tumbuhan Obat Indonesia. Jilid X. Jakarta: PT. Dian Rakyat. Hal: 653.Grovy, F.N. 2015. "Aktivitas Antimikrob dan Identifikasi Senyawa Bioaktif Ekstrak Bawang Batak (Allium chinense G. Don)". Skripsi. Bogor: Sekolah Pascasarjana Institut Pertanian Bogor. 